\title{
O MEIO AMBIENTE COMO DIREITO FUNDAMENTAL
}

\author{
Mariane Baldrighi \\ Aluna do Curso de Graduação da Faculdade de Direito da Universidade de São Paulo \\ "O reconhecimento do direito a um meio ambiente \\ sadio enriquece e reforça os direitos humanos existentes \\ e traz à tona outros direitos em novas dimensões" ${ }^{1}$
}

Resumo:

A autora aborda desde a doutrina dos Direitos Humanos, princípio sagrado do liberalismo, iniciando o trabalho com a noção de meio ambiente, os aspectos jurídicos, as conferências que vieram auxiliá-lo, e terminando com a consagração do Direito Ambiental Internacional, isto é, o conjunto de princípios e regras que geram direitos e obrigações para os Estados, as organizações internacionais e indivíduos.

\begin{abstract}
:
The author approaches from the doctrine of the Human Rights, sacred beginning of the liberalism, beginning the work with the environment notion, the juridical aspects, the conferences that came to aid him, and finishing with the consecration of the International Environmental Right, that is, the group of beginnings and rules that generate rights and obligations for States, the international organizations and individuals.
\end{abstract}

Unitermos: Direitos Humanos; Direito Ambiental Internacional; proteção constitucional.

1. Trindade, Antônio Augusto Cançado. "Meio Ambiente e Desenvolvimento: Formulação, Natureza Juridica e Implementação do Direito ao Desenvolvimento como um Direito Humano" $R P G E$, Fortaleza, 9,11: 11-42, 1992. 
I Introdução

A doutrina dos Direitos do Homem, ${ }^{2}$ não-obstante apresentar no seu bojo o jusnaturalismo, se expandiu no século XVIII, quando se tornou elemento básico da reformulação das instituições políticas. Tornou-se, portanto, um dos princípios sagrados do liberalismo.

Incorporada a nova terminologia de direitos fundamentais, a sua doutrina apresenta uma grande capacidade de incorporar desafios. Sua primeira geração enfrentou o problema do arbítrio governamental, com as liberdades públicas, ${ }^{3}$ a segunda, o dos extremos desníveis sociais, com os direitos econômicos e sociais, a terceira, hoje, luta contra a deterioração da qualidade da vida humana, com os direitos de solidariedade.

Neste sentido, verifica-se que o reconhecimento dos direitos sociais realizado pela Constituição da República de Weimar, em 1919, não pôs termo à ampliação do campo dos direitos fundamentais. O surgimento de uma terceira geração de direitos fundamentais está relacionado, não mais à vida e à liberdade, mas à qualidade de vida e à solidariedade entre os seres humanos das diferentes nações.

A doutrina destes novos direitos, denominados "de solidariedade", ainda não está solidificada, existindo muita controvérsia quanto à sua natureza e ao seu rol, uma vez que a sua identificação se deu apenas em 1979, na obra de Karel Vasak. Esta geração desenvolveu-se no plano internacional, devido às sucessivas reuniões da ONU e da UNESCO e aos conseqüentes documentos, como a Carta Africana dos Direitos do Homem e dos Povos, de 1981, e a Carta de Paris para uma nova Europa, de 1990.

Segundo Manoel Gonçalves Ferreira Filho, ${ }^{4}$ quatro são os principais desses direitos: o direito à paz, o direito ao desenvolvimento, o direito ao meio

2. A expressão "Direitos do Homen" foi repudiada pelo movimento feminista, que a considerava machista e, por isso, logrou impor, em substituição, a correta terminologia de direitos humanos, direitos humanos fundamentais, de que direitos fundamentais são uma abreviação.

3. No meio jurídico, "liberdades publicas" designam as prerrogativas reconhecidas e protegidas pela ordem constitucional. Contudo, se a expressão serve para designar os direitos declarados em 1789 e em outras declarações de cunho liberal, ela é pouco adequada num mundo que reconlıece entre as referidas "prerrogativas" direitos no plano econômico e social que transcendem as meras liberdades. Modernamente, porém, ela é empregada no sentido de direitos fundamentais.

4. Ferreira Filho, Manuel G. Direitos Humanos Fundamentais. São Paulo, Editora Saraiva, 1996. 
ambiente e o direito ao patrimônio comum da humanidade. A eles alguns acrescentam o direito à autodeterminação dos povos e o direito à comunicação.

Visando a uma maior contribuição neste novo campo jurídico, esta resenha tem como escopo analisar o Direito ao Meio Ambiente, o mais elaborado dos direitos de terceira geração, tendo em vista conceitos constitucionais, aspectos jurídicos, destacadamente no campo da responsabilidade, estudos de Direito Comparado e de Tratados Internacionais. Abordando tais características, é possível identificar o meio ambiente como direito fundamental e sua relação com os demais direitos humanos.

\section{Conceitos Preliminares}

A - Noção de meio ambiente

A Carta Magna, de 1988, utiliza a expressão "meio ambiente" consagrada em nosso Direito Positivo, que é redundante e repetitiva, pois a noção de meio já inclui a de ambiente. O conteúdo da palavra ambiente é indicativo de espaço ou lugar que envolve os seres vivos e as coisas.

O ambiente é simultaneamente um meio e um sistema de relações, formados por um conjunto de componentes físicos e de equilíbrio de forças que condiciona a vida de um grupo biológico. ${ }^{5}$ Pode ser definido como um complexo de relações entre o mundo natural e os seres vivos que influencia a sua vida e o seu comportamento.

Neste sentido, conforme aponta José Afonso da Silva, ${ }^{6}$ o ambiente compõem-se de um complexo de elementos naturais, culturais e artificiais: meio ambiente natural, abrangendo o solo, a água, o ar atmosférico, a flora, a fauna, em suma, a biosfera; meio ambiente cultural, formado pelo património artístico, histórico, turístico, paisagístico, arqueológico; meio ambiente artificial, integrado pelo espaço urbano construído, tais como edificações, ruas, praças, áreas verdes, equipamentos públicos.

5. Pierre George, L'environment, Paris, PUF, 1973.

6. José Afonso da Silva. Direito Ambiental Constitucional. 2" ed.. São Paulo, Malheiros Editores, 1995 
A civilização tem tido grande progresso, porém tem degradado constantemente a biosfera. Atualmente, vivem no mundo cerca de 5,5 bilhões de pessoas, com cerca de 1 bilhão nos países desenvolvidos e abastados, estes, sobretudo, fazendo mau-uso dos recursos da natureza e prejudicando seriamente o ecossistema. Justifica-se, pois, os diversos congressos que foram realizados, principalmente a Conferência de Estocolmo, de 1972, e a Conferência realizada no Rio de Janeiro, vinte anos depois.

\section{B - Ecologia}

Trata-se de um termo que penetrou no campo do Direito Positivo como um ambiente ecologicamente equilibrado, ecossistema. A palavra "ecologia" designa o estudo da adaptação dos organismos vivos ao meio no qual vivem e foi usada pela primeira vez em 1836, introduzida na ciência de Haeckel, famoso biólogo alemão, discípulo de Darwin, que a empregou numa nota de rodapé do livro Morfologia Geral dos Organismos.

A ecologia resume hoje em dia uma preocupação fundamental da humanidade, dada a atividade predatória do homem realizada através do emprego irracional da tecnologia e da indústria, resultando, a partir do século XX, em uma intensa degradação da natureza. Surgem conceitos novos, como o de ecossistema (1935), ecologia econômica, dinâmica de populações, sucessões bióticas.

$\mathrm{Na}$ década de 80, aparece uma teoria em ecologia denominada "Hipótese Gaia", também denominada tendência do sistema universal biocibernético-homeostase, formulada por James Lovelock e Lynn Margulis. A Terra é simbolizada com o nome da deusa grega "Gaia" "nascida após o caos e mãe universal de todos os seres' ${ }^{\prime}{ }^{7} \mathrm{O}$ sentido da tese é de que a vida se controla a si mesma, isto é, as condições físicas e químicas da superfície, os oceanos, a atmosfera, a flora e a fauna permitem condições adequadas para o surgimento da vida. Daí uma nova ciência dos sistemas que examina as inter-relações da ecosfera.

A atividade predatória do homem tem provocado uma intensa tentativa de proteger a Terra e o ambiente natural, permitindo sistemas ecologicamente equilibrados, conducente a evitar maiores tragédias.

7. Botkin, Daniel B. Repensando o ambiente, Diálogo, 25, 3:60-5, 1992; Commelin, Pierre. Nova mitologia grega e romana, 7" ed. Briget, 1941.; Lovelock. Gaia: a new look at life on Earth, 1979. 


\section{A biodiversidade}

A biodiversidade significa o conjunto das espécies animais e vegetais do planeta. Há uma certa dificuldade de estimar o número de espécies em extinção, porém os especialistas calculam que cerca de um quarto da diversidade biológica da Terra corre o risco de extinção no espaço de trinta anos.

Conforme o Programa das Nações Unidas para o Meio Ambiente (PNUMA), uma das principais ameaças à biodiversidade é a devastação das atuais florestas tropicais. As matas tropicais agasalham mais da metade das espécies do planeta, porém cobrem tão-somente $7 \%$ da superfície da Terra.

Os países desenvolvidos já devastaram as suas matas, enquanto que os subdesenvolvidos ainda, em boa parte, as conservam; daí o conflito entre ambos, pois os países ricos condenam em demasia os em desenvolvimento, procurando bloquear o desmatamento nas florestas tropicais, como no Brasil tem sido feita uma grande campanha contra a queima de florestas tropicais. Formou-se este antagonismo: os países ricos detêm a tecnologia, os países pobres monopolizam a diversidade biológica ou a biodiversidade. Algumas vezes surgem acordos como, por exemplo, a indústria farmacêutica Merck que utiliza uma espécie de planta medicinal - que celebrou um acordo com o Governo da Costa Rica, comprometendo-se a investir um milhão de dólares no levantamento da biodiversidade lá existente.

IIl Aspectos jurídicos do meio ambiente

A Lei n. 6.938, de 31.08.81, no seu art. $3^{\circ}$ I, conceitua o meio ambiente como:

"o conjunto de condições, leis, influências, interações de ordem fisica, química e biológica, que permite, abriga e rege a vida em todas as suas formas"

É este meio ambiente objeto do Direito Público, em particular do Direito Ambiental, assegurado pelo art. $225 \mathrm{da} \mathrm{CF}$, desdobramento do direito à vida, 
o primeiro dos direitos, como se apresenta no caput do art. $5^{\circ}$ da Magna Carta. Sem o meio ambiente adequado não há vida.

Trata-se, pois, de um direito absoluto, tal como o direito à vida, na medida em que é "um direito fundamental, não-sujeito à institucionalização juridica, e o é, também, enquanto direito efetivável e passível de garantia perante todos, que têm de se abster de atos, de comportamentos que violem esse direito, dentro do chamado dever geral de abstenção" 8

Simultaneamente, caracteriza-se como direito comum de todos, e todos têm a obrigação, dentro da óptica do moderno Direito Social, de defender e preservar o bem-objeto desse direito e de atender à sua função social.

Conseqüentemente, regula-se não o conteúdo desse direito, já que é absoluto, mas os limites de direitos sobre os bens ambientais e o respectivo exercício. Nesse conjunto, encontram-se os instrumentos jurídico-ecológicos, como o estudo de impacto ambiental, as reservas ecológicas, tudo a desembocar na responsabilidade pelas agressões e lesões ao meio ambiente tanto na órbita civil quanto na penal, a abranger as pessoas jurídicas.

Por se tratar de um direito comum de todos, solidário, exercitável e passível de efetivação e de proteção individual, em termos de legitimação no uso dos meios processuais correspondentes, estes não apenas estão franqueados aos Poderes Públicos, ao Ministério Público ou outras instituições, mas igualmente a cada pessoa física, porque como Direito Social, o Direito Ambiental envolve a participação do Poder Público, da sociedade civil, de cada um com vistas ao fortalecimento nacional e internacional da luta em favor do meio ambiente.

Faz-se fundamental além do "fortalecimento, individual e coletivo, da moralidade, do civismo, do amor a si mesmo e ao próximo, pois que a agressão ao meio ambiente se insere no complexo de violência, que se manifesta das mais diversas formas e em que está imersa a humanidade" 9 também uma educação ambiental, conforme o inciso VI do citado art. 225:

8. Sérgio de Andréa Ferreira, A natureza juridica do meio ambiente, in Boletim de Direito Administrativo, 11:680-81, 1994.

9. Id., ibid. 
"promover a educação ambiental em todos os níveis de ensino e a conscientização pública para a preservação do meio ambiente"

Conforme os litígios de Direito Ambiental, que envolvem a "justiça jurídica e a justiça social", pode-se identificar, no regime da vigente Constituição Federal, uma ação ambiental pública, uma ação ambiental popular, uma ação ambiental individual, conforme a legitimação para a sua propositura, ou seja, no Brasil, efetivado por via de ação civil pública (CF art. 129, III) ou popular (CF, art. $5^{\circ}$ LXXIII).

Em se tratando da classificação dos bens ambientais, o desembargador do TRF Sérgio de.Andréa Ferreira, determina quatro classes de domínios: o domínio público, o particular, o comum de todos, o social. A própria Magna Carta identifica algumas áreas como patrimônio nacional, no art. $225, \S 4^{\circ}$ :

"A Floresta Amazônica brasileira, a Mata Atlântica, a Serra do Mar, o Pantanal Mato-Grossense e a Zona Costeira são patrimônio nacional, e sua utilização farse-á, na forma da lei, dentro de condições que assegurem a preservação do meio ambiente, inclusive quanto ao uso de recursos naturais"

São todos, segundo declara o desembargador, no entanto, bens ambientais porque "exercem função ambiental e, nessa mensuração, estão afetados à nossa esfera de vida e integram o meio ambiente. Por isso, com muita propriedade, a CF alude à função ecológica desses bens" no inciso VII do art. 225 :

"proteger a fauna e a flora, vedadas, na forma da lei, as práticas que coloquem em risco sua função ecológica, provoquem a extinção de espécies ou submetam os animais a crueldade" 
Existe uma ampla legislação protetora tanto da fauna quanto da flora, incluindo códigos, como os Código de Caça (Lei n. 5.197, de 03.01.1967), da Pesca (Decreto-Lei n. 221, de 28.02.1967) e o Florestal (Lei n. 4.771, de 15.09.1965), cujos dispositivos são geralmente descumpridos.

IV O ecodesenvolvimento ou desenvolvimento sustentado: o conflito entre o direito ao meio ambiente e ao desenvolvimento

"O homem de hoje usa e abusa da natureza como se fosse o último inquilino deste desgraçado planeta, como se atrás dele não se anunciasse um futuro. A natureza converteu-se assim num bode expiatório do progresso" 10

Em aproximadamente quatro séculos de industrialização, representando menos que os milênios da era agrícola, houve uma drástica depredação do meio ambiente, provocando a morte de rios, chuvas ácidas, extinção da biodiversidade, destruição de monumentos e bens culturais.

Como destruidores da natureza cabe mencionar cerca de um milhão de toneladas de petróleo vazadas anualmente nos oceanos, os acidentes nucleares de Three Mile Island e de Chernobyl, os testes nucleares de Mururoa, grandes marés negras do Atlântico Norte, cerca de 180 milhões de toneladas anuais de lixo doméstico, hospitalar ou industrial só dos EUA, o próprio impacto da destruição humana em imponentes relíquias da arquitetura. Os ataques da chuva ácida que ameaçam a beleza da alvenaria gótica da secular catedral francesa de Rouen. A biodiversidade apresenta um ritmo alucinante de extinção. Dez por cento das espécies de plantas do mundo estão ameaçadas de extinção definitiva, e com elas aproximadamente trinta tipos de animais e insetos que dependem delas para a sua sobrevivência."

10. Ramón Martín Mateo, Derecho ambiental, Madrid, Instituto de Estudios de Adminstración Local, 1977

11. Carlos Roberto de Siqueira Castro, O direito ambiental e o novo humanismo ecológico, $R F$. $317: 68,1992$ 
Não-obstante, dificilmente se pode abordar o direito a um meio ambiente sadio em isolamento, porque não se pode considerá-lo sem referência a outro direito do gênero, a saber, o direito ao desenvolvimento como um direito humano. Neste contexto, é mister destacar a necessidade de conciliação do processo do desenvolvimento com a preservação do ambiente, formulando um novo humanismo ecológico e a substituição de uma economia de degradação por uma economia de preservação do ambiente.

Por isso é que se fala de um desenvolvimento sustentado (sustainable development), ou seja, como assinala Carlos Roberto Siqueira de Castro, "o progresso civilizatório compatibilizado com os padrões de preservação da natureza" 12

Divulgou-se a expressão desenvolvimento sustentado ou ecodesenvolvimento a respeito de uma política ambiental que não-bloqueie o desenvolvimento, porém com uma gestão racional dos recursos naturais. $\mathrm{O}$ desenvolvimento sustentado pode ser entendido como o "desenvolvimento que atende às necessidades do presente sem comprometer a capacidade das futuras gerações atenderem às suas próprias necessidades, isto é, melhorar a qualidade de vida humana dentro dos limites da capacidade de suporte dos ecossistemas" 13

Por conseguinte, como abordou Cançado Trindade, pode ocorrer que o "principio do 'desenvolvimento sustentável' forneça um possível vínculo entre o direito ao desenvolvimento e o direito a um meio ambiente sadio. O meio ambiente $e$ o desenvolvimento hão de ser enfocados conjuntamente, o que se aplica a regiões desenvolvidas assim como em desenvolvimento do mundo, criando obrigações para todos tendo em mente a comunidade internacional como um todo, e as gerações presentes assim como futuras: nesse sentido o desenvolvimento sustentável veio a ser tido não-só como um conceito, mas como um princípio de direito internacional contemporâneo" 14

\section{Id., ibid.}

13. Cuidando do planeta Terra (uma estratégia para o futuro da vida). São Paulo. publicação conjunta de UICN União Internacional para a Conservação da Natureza, PNUMA Programa das Nações Unidas para o Meio Ambiente e WWF - Fundo Mundial para Natureza, 1991.

14. Antônio Augusto Cançado Trindade, Meio Ambiente e Desenvolvimento: formulação, natureza jurídica e implementação do direito ao desenvolvimento como um direito humano, Revista da Procuradoria Geral do Estado do Ceará, Fortaleza - 9(11):11-42, 1992. 
A Assembléia Geral das Nações Unidas na Resolução n. 44/228, de 22.12.89, a Declaração de Brasília sobre o Meio Ambiente, adotada na Reunião de cúpula Latino-Americana e Caribenha, de 1989, a Declaração Ministerial sobre Desenvolvimento Sustentável e Ambientalmente Sadio de Bangkok, de 1990, o Simpósio de Beijing sobre Países em Desenvolvimento e Direito Ambiental Internacional, de 1991, afirmam e insistem na promoção do desenvolvimento sustentável e ambientalmente sadio em todos os países; reconhecem que o meio ambiente e o desenvolvimento eram indivisíveis e não poderiam ser considerados em isolamento um do outro, relacionando-se o conceito de interesse comum da humanidade tanto com o meio ambiente quanto com o desenvolvimento; acrescentam que o desenvolvimento sustentável incluía o fomento do crescimento econômico, o atendimento de necessidades humanas domésticas básicas (atinentes à saúde, nutrição, educação, habitação) e a erradicação da pobreza de modo a propiciar a todos uma vida de dignidade em um ambiente limpo, seguro e sadio. A esse respeito, o relatório do Simpósio de Beijing afirmou que: "havia vínculos entre os domínios da proteção ambiental e da proteção dos direitos humanos fornecidos principalmente pela concentração em determinados direitos humanos fundamentais (inter alia, o direito à vida e o direito à saúde) e que a emergência do direito a um meio ambiente sadio e do direito ao desenvolvimento visava fortalecer, ao invés de restringir, outros direitos, dadas suas indivisibilidade e inter-relação" 15

V - As conferências de Estocolmo de 1972 e a Eco/92

O grande marco do direito ao meio ambiente está na Declaração de Estocolmo. Visando à defesa do planeta Terra em face da devastação descomedida e irracional, de 5 a 16 de junho de 1972, 114 países enviaram seus representantes para uma reunião na Suécia a fím de se buscar soluções técnicas para a poluição ambiental. Nela se enuncia como primeiro princípio:

"O homem tem direito fundamental à liberdade, à igualdade e ao gozo de condições de vida adequada em um ambiente que esteja em condições de permitir uma

15. UNESP, Beijing Symposium on Developing Countries and International Environmental Law, (rapporteurs A.A. Cançado Trindade (Brasil) e A. Malhotra (Índia)), Beijing, 1991 (relatório tínal). 
vida digna $e$ de bem-estar; tem ele a grave responsabilidade de proteger e melhorar o ambiente para as gerações presentes e futuras. A esse respeito, a política que promover ou perpetuar a discriminação ou a segregação racial, a opressão colonial ou de qualquer espécie, ou a dominação estrangeira, continuam condenadas e deverão ser eliminadas"

Posteriormente, a Assembléia das Nações Unidas e diversas organizações não-governamentais, com a mesma finalidade, convocaram a Conferência das Nações Unidas sobre Meio Ambiente e Desenvolvimento, que se realizou de 3 a 14 de junho de 1992, no Rio de Janeiro, reafirmando os princípios enunciados na Conferência de Estocolıno. Ela é a segunda Conferência da ONU sobre o meio ambiente. Contudo, na Declaração de 92, a formulação do princípio primeiro é mais sutil:

"Os seres humanos estão no centro das preocupações com o desenvolvimento sustentável. Têm direito a uma vida saudável e produtiva, em harmonia com a natureza"

Cumpre mencionar que, na Eco/Rio, adicionaram-se outros instrumentos de grande importância: a Convenção sobre a Biodiversidade, visando à conservação da diversidade biológica, o uso sustentável de seus componentes e a distribuição justa e eqüitativa dos benefícios que provenham da utilização das fontes genéricas, incluindo o acesso apropriado a essas fontes e adequada transferência de bjotecnologias. Outro instrumento refere-se à adoção de acordos sobre a conservação e o desenvolvimento sustentável de todos os tipos de florestas, e finalmente, sobre o comitê de negociação para uma convenção sobre a mudança climática.

Em tal Conferência, ao se debater a proteção das florestas, houve a resistência do Brasil e de outros países que se opunham a uma convenção que disciplinasse só as florestas tropicais, alegando que se deveria abranger todos os tipos de florestas, incluindo as boreais, mediterrâneas e temperadas. 
Observa-se que na Eco/92, travou-se o duelo entre as nações ricas e as nações pobres. De um modo geral, os países reconhecem a necessidade de um controle sobre a exportação da sua riqueza biológica, como fonte de alimento, remédios, etc. Entretanto as divergências com os países ricos por parte dos países do Terceiro Mundo começaram quando aqueles se utilizaram de tal patrimônio com a ajuda da biologia molecular, afirmando que tal material genético era propriedade universal e deveria ficar em estado de natureza buscando a sua preservação. Os países mais pobres defenderam a soberania de suas regiões, onde se encontra tal material genético, pensando em uma compensação pelo uso de sua diversidade biológica ou biodiversidade.

Não-obstante, convém lembrar que, desde a Conferência de Estocolmo, em 1972, o mundo viu a destruição de duzentos bilhões de hectares de bosques, as áreas desérticas aumentaram em mais de 120 milhões de hectares, além do dano causado pelo dióxido de carbono na camada de ozônio.

VI O dano ecológico e suas conseqüências no campo da responsabilidade

\section{A Responsabilidade civil}

O termo dano, significando toda alteração desvantajosa para um titular ou uma coisa, em seu sentido amplo, pode ser entendido como a lesão de qualquer bem jurídico. Sendo a natureza um bem jurídico, o dano ecológico define-se como a efetiva diminuição do patrimônio da mãe-Terra.

Cada dia aumenta a importância do estudo sobre o dano ecológico pela necessidade de amparar a natureza da atividade predatória do homem, uma vez que todo prejuízo necessita ser reparado. O dano ecológico sempre existiu como uma forma de lesão, tanto às pessoas quanto às coisas no ambiente em que vivem. Pela atividade predatória humana, o dano ecológico sofre uma profunda agravação geométrica por causa do perigo da ação humana na conquista da natureza, prejudicando o equilíbrio ecológico. Daí advém uma responsabilidade civil decorrente da relação de causalidade entre o dano e a ação do sujeito ativo que produziu o dano.

O dano ambiental ou o dano ecológico necessita de três requisitos básicos, clássicos da doutrina da responsabilidade civil, para caracterizar a responsabilidade: o fato, o dano e o nexo de causalidade entre eles. 
Entre as atividades lesivas ao meio ambiente, a Constituição de 1988 dedica três parágrafos àquelas suscetíveis de causarem danos ecológicos, mencionando especificamente a mineração, a utilização da energia nuclear e a devastação, com dispositivo dedicado exclusivamente à reparação dos danos ambientais:

"§ $1^{\circ}$ - inc. VII. Para assegurar a efetividade desse direito, incumbe ao Poder Público: proteger a fauna e a flora, vedadas, na forma da lei, as práticas que coloquem em risco. sua função ecológica, provoquem a extinção de espécies ou submetam os animais a crueldade"

$" \S 2^{\circ}$ Aquele que explorar recursos minerais fica obrigado a recuperar o meio ambiente degradado, de acordo com solução técnica exigida pelo órgão público competente, na forma da lei"

$" \S 6^{\circ}$ As usinas que operem com reator nuclear deverão ter sua localização definida em lei federal, sem o que não poderão ser instaladas"

A exploração dos recursos minerais no Brasil tem sido feita de modo desordenado e irracional desde o século XVII, como, por exemplo, a exploração garimpeira, poluindo os rios com mercúrio e provocando a sua morte. Tanto a Constituição quanto o Código de Minas (Decreto-Lei n. 227, de 28.02.1967) prevêem a recuperação de tal meio ambiente, mediante soluções técnicas formalizadas na lei e determinadas pelo Poder Público. Entretanto, tal mandamento que já existia na lei ordinária, passa para a lei constitucional com eficácia praticamente nula.

Problemas da Responsabilidade Civil nos Danos ao Meio Ambiente

Os danos ao ambiente podem ser causados tanto pelas pessoas físicas quanto pelas empresas. Naqueles casos muito comuns de dano ambiental provocado pela atividade industrial foi desenvolvido o princípio do poluidor-pagador ou 
príncipe pollueur-payer (PPP). Segundo Sérgio Roxo da Fonseca, o sentido de tal princípio é de que o dano ecológico deve ser indenizado pelo beneficiário, entendido como tal o próprio causador do dano ou adquirente do produto para quem foi fabricado o mesmo e que provocou o dano. Este último paga o valor ampliado do custo ambiental quando adquire o produto. ${ }^{16}$

Tal princípio foi adotado pela Conferência de Estocolmo, para minorar os efeitos negativos de impactos ambientais nocivos à natureza:

"Principio 21 Consoante a Carta das Nações Unidas e os princípios do Direito Internacional, os Estados têm o direito soberano de explorar suas riquezas de acordo com a sua política ambiental, e a responsabilidade de assegurar que as atividades exercidas dentro de suas jurisdições ou sob o seu controle não prejudiquem o meio ambiente de outros Estados, ou de áreas situadas fora da jurisdição nacional.

Principio 22 Os Estados colaborarão para ulteriormente aperfeiçoar as leis internacionais referentes à responsabilidade e o ressarcimento às vitimás da poluição e de outros danos ambientais, por atividades realizadas dentro do âmbito territorial ou sob o controle de tais Estados, em zonas que ultrapassarem suas jurisdições"

No Brasil, a cobrança do custo ambiental ou poluidor ficou preceituada no art. $14, \S 1^{\circ}$, da Lei n. 6.938, determinando a obrigação de indenizar o dano causado ao ambiente e também a terceiros afetados por tal atividade, mesmo sem culpa. É a responsabilidade objetiva.

O tratadista especialista em Direito Ambiental, Paulo Afonso Leme Machado, leciona que "há sempre o perigo de se contornar a maneira de se reparar

16. Sérgio Roxo da Fonseca, O Ministério Público e o dano ecológico, Justitia, publicação da Procuradoria-Geral da Justiça do Estado de São Paulo, 113:146, 1981. 
o dano, estabelecendo-se uma liceidade para o ato poluidor, como se alguém pudesse afirmar: 'Poluo mas pago' Entretanto o sentido do princípio 'poluidorpagador' que agora está sendo introduzido na esfera do direito internacional, não tem por finalidade coonestar a poluição, mas impedir que o dano ecológico fique sem reparação. E continua que para obrigar "o Poder Público a ser prudente $e$ cuidadoso no vigiar, orientar, e ordenar a saude ambiental nos casos em que haja prejuizo para as pessoas, para a propriedade ou para os recursos naturais, mesmo com a observância dos padrões oficiais, o Poder Público deve responder solidamente com o particular" 17

A esse respeito cabe mencionar o art. 45, apartado 3, da Constituição espanhola de 1978, conforme o qual quem violar a lei reguladora da matéria sofrerá sanções penais ou, "em seu caso, administrativas, assim como a obrigação de reparar o dano causado"

É importante salientar que a administração pública tem responsabilidade solidária pelo dano causado, mesmo com licença. Toshio Mukai ${ }^{18}$ salienta também que a solidariedade pode surgir no caso de licenças ou autorizações legais, por força de um critério objetivo, desde que haja um dano especial ao meio ambiente, afetando pessoas da comunidade. Em diversas hipóteses pode surgir a responsabilidade da administração pública, seja com a culpa in vigilando ou in omittendo.

A legislação deve evoluir e consolidar o princípio de que as pessoas jurídicas, públicas ou privadas, ou as pessoas físicas são responsáveis pelos danos causados ao meio ambiente. O agente causador, além de responsabilidades decorrentes da sua conduta, deve promover a recuperação plena do meio ambiente degradado.

17. Paulo Afonso Leme Machado, Direito ambiental brasileiro, 2" ed., São Paulo, Revista dos Tribunais, 1989.

18. Toshio Mukai, Responsabilidade solidária da administração por danos ao meio ambiente, Justitia, 114:75-80, jan/mar. 1988. 
B Responsabilidade penal

No $\S 3^{\circ}$, a Constituição prevê o crime ecológico:

"As condutas e atividades consideradas lesivas ao meio ambiente sujeitarão os infratores, pessoas fisicas ou jurídicas, a sanções penais e administrativas, independentemente da obrigação de reparar os danos causados."

A grande novidade da Constituição é a introdução da responsabilidade penal por danos causados ao meio ambiente, tanto para as pessoas físicas quanto para as jurídicas, o que não ocorria no texto constitucional anterior, que só a previa para as primeiras. Tal responsabilidade tornou-se viável na esfera de crimes ecológicos no texto constitucional vigente. Necessita, contudo, de regulamentação por normas infraconstitucionais.

Os crimes ambientais dispostos na legislação comum encontram-se basicamente nos Capítulos I Crimes de Perigo Comum e III - Crimes Contra a Saúde Pública, do Título VIII do Código Penal, que elenca os crimes contra a incolumidade pública. No entanto, outros tipos penais poderão ser considerados crimes ambientais, caso a conduta do agente infrator acabe lesionando um bemambiental (água, cavidades naturais subterrâneas, energia, espaços territoriais protegidos e seus componentes, fauna, flora, florestas, ilhas, mar territorial e praias) ou alguma atividade relacionada com o meio ambiente (caça, garimpo, irrigação, mineração, etc).

São considerados crimes ambientais de perigo comum:

$\Rightarrow$ Incêndio admite forma dolosa (art. 250 , caput) e culposa $\left(\$ 2^{\circ}\right.$ do art. 250);

$\Rightarrow$ Explosão forma dolosa (art. 251) e culposa ( $\S 3^{\circ}$ do art. 251);

$\Rightarrow$ Uso de gás tóxico ou asfixiante forma dolosa (art. 252) e culposa (parágrafo único);

$\Rightarrow$ Fabrico, fornecimento, aquisição, posse ou transporte de explosivos ou gás tóxico ou asfixiante - só adınite a forma dolosa (art. 253); 
$\rightarrow$ Inundação admite formas dolosa e culposa (art. 254, caput);

$\Rightarrow$ Subtração, ocultação ou inutilização de material de salvamento só dmite forma dolosa (art. 257);

$\Rightarrow$ Difusão de doença ou praga dolosa (art. 259, caput), culposa parágrafo único).

São considerados crimes contra a saúde pública:

$\rightarrow$ Envenenamento de água potável ou de substância alimentícia ou nedicinal admite forma dolosa (art. $270, \S 1^{\circ}$ ) e culposa $\left(\S 2^{\circ}\right)$;

$\Rightarrow$ Corrupção ou poluição de água potável - dolosa (art. 271) e ulposa (parágrafo único).

Ainda no Código Penal, há outros tipos penais considerados crimes mbientais:

$\Rightarrow$ Dano em floresta particular (art. 163);

$\Rightarrow$ Dano em floresta da União, Estado, Município, concessionário de erviços públicos ou sociedade de economia mista (art. 163 pena mais grave);

$\rightarrow$ Dano por abandono de animais em floresta (art. 164);

$\Rightarrow$ Supressão ou desdobramento de tapume, marco ou qualquer outro inal indicativo de linha divisória, para apropriar-se, no todo ou em parte, de coisa móvel (art. 161);

$\Rightarrow$ Resistência, desobediência e desacato quando praticados por gentes a serviços da proteção da fauna ou flora;

$\Rightarrow$ Furto quando o bem-ambiental pertencer à União Federal (art. $55)$;

$\Rightarrow$ Falsidade e Uso de Documento Público - adulteração de uma guia lorestal para o transporte de madeira, por exemplo (art. 297).

Observa-se que o nosso Direito Penal precisa aperfeiçoar-se no stabelecimento de normas de punibilidade das condutas nocivas ao meio ambiente, ois tais preceitos não são suficientes. Em nosso Direito Penal, segundo Heleno 决udio Fragoso, prevalece o princípio da reserva legal, também denominado rincípio da legalidade das penas e delitos. Não se pode prever nem violar senão quilo que está previsto na lei, conforme o art. $1^{\circ}$ do nosso Código Penal. Daí a ecessidade da criação de novos tipos penais aplicados à ecologia. Por tipo deve-se 
entender "o modelo legal do comportamento proibido, compreendendo o conjunto das características objetivas e subjetivas do fato punido. 19

$\mathrm{Na}$ Itália, ocorreu também tal dificuldade pela falta de tipos penais suficientes, o que levou a jurisprudência italiana a suprir a lacuna legislativa mediante uma aplicação extensiva da norma penal ecológica. ${ }^{20}$

Questiona-se então onde incluir o novo tipo penal ecológico, se na Parte Especial do Código Penal ou em um Direito Penal Administrativo. Parece que os dois ramos do Direito devem ser levados em conjunto, não-bastando somente um instrumental repressivo contido no Direito Penal, como ainda a disciplina administrativa direcionada para a prevenção.

Outra indagação importante é saber se a responsabilidade penal por lesão ao meio ambiente permite a punibilidade de ação nociva, mas que tenha sido licenciada pela autoridade competente. Uma linha doutrinária pretende que a licença dada pela autoridade administrativa justifica, naturalmente, a conduta. Posição contrária é do tratadista do Direito Ambiental brasileiro, Paulo Afonso Leme Machado, observando que "a constituição deu um sério passo para a punição da ofensa ao ambiente, pois, agora, mesmo a conduta ou atividade autorizada pelo Poder Público, desde que lesiva, poderá ser incriminada penalmente" 21 Tal opinião encontra também respaldo no Direito Comparado. No Japão, a sua Suprema Corte condenou empresa que poluiu o meio ambiente, embora autorizada pela autoridade administrativa e seguisse as suas prescrições para reduzir o potencial da carga poluidora. Portanto, verifica-se a atuação do Sistema Judiciário de proteção interna dos direitos fundamentais com autoridade para rever os atos administrativos e anulando aqueles que não são convenientes ao interesse público.

Adicionalmente, é mister saber como a pessoa jurídica pode ser penalizada em crime ecológico. No Direito suíço, adota-se a pena pecuniária dimensionada de acordo com as condições econômicas da empresa, e não conforme o grau de culpa. O Direito italiano cogita de penas contra as empresas poluidoras, mediante o confisco dos aparelhos instrumentais utilizados na poluição hídrica. $O$

19. Heleno Cláudio Fragoso, Lições de Direito Penal: parte geral, 10 ": ed., rev. por Fernando Fragoso, Rio de Janeiro, Forense, 1986

20. Paulo José da Costa Júnior, Direito Penal ecológico, Justitia, publicação da ProcuradoriaGeral da Justiça de São Paulo, 113:68, 1981.

21. Ob. cit. 
Direito alemão penaliza as empresas com a pena de multa, varando com a qualidade do ilícito e a gravidade da culpa, e ainda com a pena de confisco de bens.

Verifica-se notória a importância da penalidade das pessoas juridicas, pois são essas que necessitam de punibilidade mais do que o indivíduo isolado, uma vez que violam mais profundamente o ambiente ecológico e especialmente a biosfera. $^{22}$

Problema da Responsabilidade Penal

A responsabilidade civil da pessoa moral é inegável, porém discute-se a responsabilidade penal das empresas, que, de regra, são as que mais danos causam ao meio ambiente. Sobre a responsabilidade penal das empresas existem duas posições diferentes no Direito Comparado. A primeira orientação é sancionar penalmente as pessoas coletivas, que se impôs na Inglaterra, França, EUA, Canadá, Austrália e Holanda. Outra orientação é a de acentuar a impossibilidade da responsabilidade penal das pessoas jurídicas, ou seja, a responsabilidade penal é pessoal, adotada em Portugal, Alemanha, Espanha e Itália. Na Argentina, ${ }^{23}$ afirma-se a limitação da capacidade penal para a pessoa, pois determiná-la também para os entes coletivos significaria a identificação de conceitos penais e civis. Na América Latina, a rota dominante é a penalização da pessoa natural, com exceção do México, Costa Rica e Cuba.

A Constituição brasileira, de 1988, fala de sanções penais contra as pessoas jurídicas, independentemente da obrigação de reparar o dano. A doutrina discute a viabilidade da aplicação de penas às pessoas coletivas. A orientação predominante é a de que as pessoas jurídicas só podem responder civil e administrativamente, porque a responsabilidade penal é de natureza e de caráter estritamente pessoais. Contudo determinadas leis especiais se opõem ao princípio de que o crime é apenas o resultado da ação humana. Nesse sentido podem ser indicadas as seguintes leis dentre várias:

$\rightarrow$ Lei n. 4.729, de 14.07.1965 (crime de sonegação fiscal) embora ressalvando que a responsabilidade penal é das pessoas físicas vinculadas com a

22. Francisco José Marques Sampaio, O dano ambiental e a responsabilidade, $R F, 317: 116-25$, 1992.

23. Eugenio Raúl Zaffaroni, Tralado de Derecho Penal: parte general, Buenos Aires, Ediar, 1981, v. 3. 
empresa sonegadora, permite a atribuição da infração penal à pessoa jurídica, conforme seu art. $6^{\circ}$

$\rightarrow$ Lei $n$. 6.435, de 15.07.1977 admite que o ente coletivo pode cometer o delito de atuação como entidade de previdência privada sem a necessária autorização, e nesse caso seus diretores e administradores incorrerão na mesma pena (art. 80).

Antônio Chaves salienta que, para prevenir e reprimir a devastação ecológica, a empresa, em casos extremos, deve ser penalmente responsabilizada, independentemente da obrigação de pagar os danos causados, porque "é ela quem se beneficia economicamente da atividade ilicita. Nada mais justo, portanto, sempre que o crime ecológico configurar a expressão de uma política econômica da empresa, venha ela ser atingida pelo direito penal especial" 24

A verdade é que já existem inúmeras leis de proteção ambiental. É preciso tão-somente aplicá-las, cabendo ao Poder Judiciário a execução da vontade concreta da lei. Cabe também salientar inúmeras sanções administrativas, sobretudo as multas e também a própria interdição do estabelecimento.

\section{Responsabilidade administrativa}

O Direito Ambiental encerra um conjunto de normas, de caráter preventivo, repressivo e reparatório, porém a tutela do meio ambiente superou ultimamente o estágio repressivo e reparatório, fundamentado em regras da responsabilidade civil e penal, para preocupar-se também com a prevenção do dano ambiental. Existem, assim, meios repressivos de proteção ao ambiente, além da sanção penal, como a sanção administrativa, ambas ocorrendo depois do dano causado.

Ao lado de tais meios repressivos, a Administração Pública também tem instrumentos de tutela ambiental, visando à reparação do dano já causado, mediante a ação civil pública. Mais tarde, surgiram os instrumentos de prevenção ao dano ecológico, entre eles, principalmente, o planejamento ambiental, o zoneamento ambiental e o EIA. ${ }^{25}$ As medidas preventivas têm por escopo limitar a margem de

24. Antônio Chaves, Responsabilidade no Direito Ambiental brasileiro, $R F, 317: 9-23,1992$

25. O Estudo de Impacto Ambiental (EIA) é de origem norte-americana e representa um estudo visando à análise das modificações que um projeto pode provocar no meio ambiente. O ElA surgiu historicamente no Direito brasileiro com a Lei n. 6.803, de 03.07.80, com esfera limitada para as áreas 
opções do administrador em benefício da comunidade, impedindo a afronta ao equilíbrio ecológico por medidas anteriores, adotadas antes da realização do projeto.

Segundo José Afonso da Silva, ${ }^{26}$ a responsabilidade administrativa "resulta de infração a normas administrativas sujeitando-se o infrator a uma sanção de natureza também administrativa: advertência, multa, interdição de atividade, suspensão de beneficios". Fundamenta-se na capacidade que têm as pessoas jurídicas de Direito Público de impor condutas aos administrados. Esse poder administrativo é inerente à Administração da União, Estados, Distrito Federal e Municípios, nos limites das respectivas competências instituicionais.

Dentre os poderes administrativos, destaca-se o poder de polícia administrativa, que a Administração Pública exerce sobre todas as atividades e bens que afetam ou possam afetar a coletividade. Como cabe às três unidades proteger o meio ambiente, também lhes incumbe fazer valer as providências de sua alçada, "condicionando e restringindo o uso e gozo de bens, atividades e direitos em beneficio da qualidade de vida da coletividade, aplicando as sanções pertinentes nos casos de infringência às ordens legais da autoridade competente" 27

$\mathrm{O}$ art. 14 da Lei n. 6.938/81 determina que o não-cumprimento das medidas necessárias à preservação ou correção dos inconvenientes e danos causados pela degradação da qualidade ambiental sujeitará os transgressores:

"I - à multa simples ou diária, nos valores correspondentes, no mínimo, a dez e, no máximo, mil BTNs, agravada em casos de reincidência específica, conforme dispuser o regulamento, vedada a sua cobrança pela União se já tiver sido aplicada pelo Estado, Distrito Federal, Território ou pelos Municipios; II - à perda ou restrição de incentivos e beneficios fiscais concedidos pelo Poder Público; III à perda ou suspensão de participação em linhas de

críticas de poluição em zona industrial. Mais tarde foi editada a Lei n. 6.938, de 31.08.81, regulando a politica nacional do meio ambiente e autorizando "a avaliação de impactos ambientais" (art. $9^{\circ}$, III).

26. José Afonso da Silva. Direito Ambiental Constitucional. $2^{\text {a }}$ ed., São Paulo, Malheiros Editores, 1995.

27. Id., ibid., p. 210, 1995. 
financiamento em estabelecimentos oficiais de crédito; IV à suspensão de sua atividade"

Pelo fato destas disposições serem gerais, aplicam-se a transgressão a qualquer norma legal disciplinadora da preservação, melhoria ou recuperação da qualidade ambiental, mesmo quando não esteja, na lei ou regulamento específico, consignada sanção para o caso. Entretanto, leis especiais podem também estabelecer sanções administrativas para as infrações às suas normas e, em tal caso, prevalecem as sanções nelas previstas.

A aplicação de sanções administrativas requer a instauração do respectivo processo administrativo punitivo, necessariamente contraditório, com oportunidade de defesa e estrita observância do devido processo legal, sob pena de nulidade da punição imposta, nos estritos termos do art. $5^{\circ}, \mathrm{LV}$, da Constituição.

É mister destacar que, em matéria de meio ambiente, inúmeras ações sem maior relevância são elevadas à categoria de infrações penais, na modalidade de contravenções. Exemplifica-se com o art. 64 do Decreto-Lei n. 221, de 1967. o mencionado Código de Pesca. Referido dispositivo estabelece que o reincidente em falhas administrativas que tornar a violá-las cometerá contravenção penal. Evidencia-se, neste sentido, a opção política do legislador que, objetivando desestimular determinada conduta, a eleva à categoria de fato contravencional.

\section{O Direito Ambiental Internacional}

O Direito Ambiental Internacional é o conjunto de princípios e regras que geram direitos e obrigações para os Estados, as organizações internacionais e indivíduos, tendo em vista a preservação do meio ambiente. O sujeito principal deste campo jurídico é o Estado, porém a função das organizações intergovernamentais e da pessoa se torna cada dia mais relevante.

Foi constituído o Programa das Nações Unidas para o Meio Ambiente (PNUMA ou UNEP) como o órgão mais importante para as questões ambientais, tendo os seus técnicos e especialistas uma profunda expertise (capacidade específica).

Diversas são as fontes do Direito Ambiental Internacional. O art. 38 do Estatuto da Corte Internacional de Justiça relaciona as seguintes: 
$\rightarrow$ Tratados - São a principal fonte. A capacidade de firmar tratados pertence não-só aos Estados, como sujeitos de direito, como ainda determinadas categorias de organizações internacionais, tais como a Convenção de Viena, entre as organizações internacionais. ${ }^{28}$ Os tratados ambientais podem ser genéricos ou específicos; ou ainda de caráter global, e regional, sub-regional ou bilateral pelo aspecto geográfico. Como exemplo de tratado regional genérico pode-se mencionar o Tratado de Cooperação Amazônica, que também tem em vista a racionalização planejada do aproveitamento da flora e da fauna da Bacia Amazônica, para obter o equilíbrio ecológico da região e a preservação de espécies, assinado em Brasília em 03.07.78. O problema do surgimento de um buraco na camada de ozônio, acima da Antártica, movimentou a opinião pública depois de um verão muito quente que surgiu na Europa, divulgando-se ainda o efeito das queimadas na Amazônia e daí o brado de alerta dos cientistas mobilizando a opinião pública, que levou à assinatura do Protocolo de Montreal. No decorrer da Conferência Eco/92, duas convenções foram estudadas: a Convenção sobre Mudanças Climatológicas, tendo em vista o combate ao efeito estufa, e a Convenção sobre Biodiversidade, ambas já mencionadas.

$\rightarrow$ Costumes internacionais devem possuir também uma base de prática geral aceita como sendo direito;

$\rightarrow$ Princípios gerais de direito sua invocação deve ser bem estabelecida e geralmente são aceitos;

$\rightarrow$ Decisões judiciárias - a posição adquirida pela jurisprudência é importante, assim como seu reconhecimento. Exemplificando, o Trail Smelter Case 'resultou numa decisão jurisprudencial sobre poluição transfronteiriça. Tal caso provém de um acordo de arbitragem entre os EUA e o Canadá, em abril de 1985 , para resolver um problema de poluição de dióxido de enxofre, provocada por uma fundição de zinco e chumbo no Canadá e com conseqüências danosas no Estado de Washington. O laudo arbitral decidiu: "nenhum Estado tem o direito de usar ou permitir o uso de seu território de tal maneira que emanações de gases ocasionam dano dentro de outro território ou sobre as propriedades ou pessoas que aí se encontrem, quando se trata de consequiencias graves e o dano seja determinado

28. G. E. do Nascimento e Silva, The 1985 Vienna Convention and the Treaty Making Power of International Organization, in German Yearbook of International Law, 1986. 
mediante provas certas e conclusivas" 29 Outra situação típica foi o caso Lannox, decidido em 1956 por sentença arbitral, a fỉm de evitar a poluição de águas do lado do território da França afetando a Espanha.

$\rightarrow$ Doutrina dos autores de melhor qualificação - tem posição de destaque, embora ultimamente a Corte Internacional de Justiça tenha entendido que um pronunciamento desse órgão vale mais do que as opiniões dos juristas isolados, por mais importante que sejam.

\section{Conclusão}

Pelo exposto, observa-se que é forte a inter-relação entre os direitos fundamentais, ou seja, ao se reconhecer o direito a um meio ambiente sadio, os jáexistentes direitos humanos de primeira e segunda gerações são enriquecidos, porque abordando o comprometimento finalístico da função ambiental (propiciar uma sadia qualidade de vida), não se cuida somente de ensejar a sobrevivência, mas de garantir uma existência hígida, em decorrência da preservação do equilíbrio ecológico, ou seja, garantir a vida em sua plenitude, com seus desdobramentos da saúde, da liberdade, da segurança, da igualdade de indivíduos e de Nações. Não-obstante, são cristalizados outros direitos em novas dimensões, como o tão-necessário direito de participação dos cidadãos, que requer a efetividade dos direitos à informação e à educação em questões ambientais.

Do mesmo modo, pode-se buscar a proteção ambiental mediante a reivindicação de direitos existentes, isto é, direito à privacidade, direito ao gozo pacífico das posses de cada um, como indica a jurisprudência recente da Convenção Européia de Direitos Humanos. Percebe-se, assim, a indivisibilidade dos direitos humanos: afirmado como um direito fundamental, o direito a um meio ambiente sadio, muito mais do que acarretar restrições ao exercício de outros direitos, enriquece o rol dos direitos fundamentais consagrados.

Logo, por refletir um importante valor social; ser relevante, mesmo em grau variável num mundo de diferentes sistemas de valor, ou seja, devido ao impacto e à forte proteção internacional, a ponto de ser elegível para reconhecimento com base numa interpretação das obrigações estipuladas na Carta das Nações Unidas,

29. Kerin J. Madders, Trail Smelter Case, in Encyclopaedia of public international law, v. 2, pp. 276-283; Frederick Kirg's, Thechnological challenge to the shared environment, American Journal of International Lav, v. 66, p. 291, 1972; American Lair Institute, Restatement, v. 2, p. 109. 
numa reflexão a propósito de normas jurídicas costumeiras ou nos princípios gerais de direito; e ser capaz de alcançar um alto nível de consenso internacional, é que o direito ao meio ambiente é identificado como um direito fundamental.

São Paulo, dezembro de 1997.

\section{Bibliografia}

Constituição da República Federativa do Brasil-1988. Juarez de Oliveira (org.). $13^{\text {a }}$ edição, São Paulo, Saraiva, 1996.

Código Penal. Maurício Antonio Ribeiro Lopes (coord.). São Paulo, Editora Revista dos Tribunais, 1996.

ALVES, Alaôr Caffé. "Preservação do meio ambiente e desenvolvimento sócioeconômico". RPGE, São Paulo, (29): 293-316, 1988.

ANDRADE, Lourenço Agostini. "A tutela ao meio ambiente e a Constituição" Revista da Associação dos Juízes do RS, 16(45):71-99, 1989.

ARAUJO, Luís A. David. "Direito constitucional e meio ambiente" Revista do Advogado, São Paulo, (38):63-70, 1992.

ARMELIN, Donaldo. "Tutela jurisdicional do meio ambiente" Revista do Advogado, São Paulo, (37):48-62, 1992.

BARROSO, Luís Roberto. A proteção do meio ambiente na Constituição brasileira". Rio de Janeiro, Revista Forense, (317):161-78, 1992.

BONALUME, Wilson L. "Crimes contra o meio ambiente" Revista dos Tribunais, 78(644):229-55, 1989.

CARVALHO, Sebastião C. G. "Direito do Ambiente e sociedade". Revista do Curso de Direito da Universidade Federal de Uberlândia, 17(112):401-12, 1988.

CUADRA, Enrique Evans. "El derecho a vivir en un ambiente libre de contaminación su real alcance" Temas de Derecho, Chile, 8(1):79-87, 1993.

CUSTODIO, Helita B. "Anteprojeto de lei de consolidação das leis federais do meio ambiente: incompatibilidades jurídico-ambientais" Revista de Direito Civil, Imobiliário e Empresarial, São Paulo, 16(61):58-72, 1992.

FERREIRA, Sérgio de Andréa. "A natureza jurídica do meio ambiente" $B D A$, 10(11):680-1, 1994.

FERREIRA FILHO, Manoel Gonçalves. Direitos Humanos Fundamentais. São Paulo, Editora Saraiva, 1995. 
FERREIRA, Pinto. Comentários à Constituição Brasileira - v. 7. São Paulo, Editora Saraiva, 1995.

FIORILlO, Celso A. Pacheco. "Ação Popular e a defesa do meio ambiente" Revista do Advogado, (37):27-35, 1992.

FREITAS, Vladimir Passos de. Direito Administrativo e Meio Ambiente Curitiba, Juruá, 1995.

GONZALEZ BALLAR, Rafael. "La protección del medio ambiente en centro America" Revista de Ciencia Jurídica, Costa Rica, (67):127-67, 1990.

LAUBE, Vitor Rolf. "Perfil constitucional do meio ambiente" Caderno de Direito Constitucional e Ciência Política, São Paulo, 1(4):216-26, 1993.

PIOVESAN, Flávia. "O direito ao meio ambiente e a Constituição de 88: diagnóstico e perspectivas". Caderno de Direito Constitucional e Ciência Política, 1(4):7597, 1993.

REINALDI, Gustavo \& BUSSO, Fani. "El medio ambiente como bien protegido en la Constituición de Cuba y la Ley del ambiente" Revista de la Faculdad de Derecho y Ciencias Sociales, Universidad Cordoba, 1(2):529-47, 1993.

RODRIGUEZ, Fernando Dougnac. "Los bienes que la naturaleza ha hecho comunes a los hombres, como fundamento jurídico en Chile". Temas de Derecho, Chile, 8(1):89-102, 1993.

SILVA, José Afonso da. Direito Ambiental Constitucional. São Paulo, Malheiros, 1995.

TRINDADE, Antônio Augusto Cançado. "Meio Ambiente e Desenvolvimento: formulação, natureza jurídica e implementação do direito ao desenvolvimento como um direito humano". RPGE, Fortaleza, 9911): 11-42, 1993. 